\title{
AVALIAÇÃO DAS ATIVIDADES ENZIMÁTICAS DE PECTINASE E POLIGALACTURONASE COM DIFERENTES PROPORÇÕES DE CASCA DE COCO VERDE E SABUGO DE MILHO
}

\author{
K. M. A. SANTOS ${ }^{1}$, M. L. ARAÚJO' ${ }^{2}$, G. F. $\operatorname{SILVA}^{1}$, A. K. S. ABUD ${ }^{2,3}$ e A. M. OLIVEIRA Jr ${ }^{1,3}$ \\ ${ }^{1}$ Universidade Federal de Sergipe, Programa de Pós-Graduação em Engenharia Química \\ ${ }^{2}$ Universidade Federal de Alagoas, Programa de Pós-Graduação em Engenharia Química \\ ${ }^{3}$ Universidade Federal de Sergipe, Departamento de Tecnologia de Alimentos \\ E-mail para contato: kryslainealmeida@gmail.com
}

\begin{abstract}
RESUMO - A região Nordeste possui uma economia baseada na produção agrícola, gerando grande quantidade de resíduos sólidos, compostos por cascas, sementes, restos de polpa, entre outros. O processo de fermentação semi-sólida (FSS) tem papel de destaque no aproveitamento destes resíduos, visto ser um processo simples, de fácil recuperação de metabólitos gerados e de síntese de compostos de alto valor agregado, como enzimas, dentre as quais estão as pectinolíticas, muito aplicadas na área alimentícia. O presente trabalho utiliza a metodologia do planejamento experimental fatorial completo $2^{2}+3$, com triplicata de todos os experimentos, e análise de superfície de resposta para avaliar a influência da umidade e proporção da mistura de resíduos, casca de coco verde e sabugo de milho, na síntese das enzimas pectinase e poligalactunorase. $\mathrm{O}$ extrato enzimático produzido alcançou atividade para pectinase de 13,76 U/g e de 45,08 U/g para a poligalactunorase. Através da metodologia de superfície de resposta avaliaram-se as variáveis independentes umidade e proporção de resíduo sobre a síntese destas enzimas. Verificou-se que a umidade e a proporção foram significativas para atividade enzimática da pectinase, com nível de significância de 0,05 . Somente a umidade foi significativa para a atividade poligalacturonase, com o mesmo nível de significância.
\end{abstract}

\section{INTRODUÇÃO}

O desperdício de alimentos causa grande impacto na sociedade e meio ambiente. As perdas são observadas em toda cadeia produtiva o que estabelece uma necessidade de aproveitamento tanto dos alimentos de maneira integral quanto a possibilidade de manutenção do consumo habitual com utilização de resíduos para novos produtos alimentícios. O aproveitamento de resíduos de frutas, principalmente cascas, como matéria prima no processamento de novos alimentos e na produção de enzimas é de grande interesse ambiental e social. Devido a isso, alguns processos biotecnológicos vêm se apresentando como uma alternativa de utilizar esses materiais, agregando alto valor a produtos de descarte com a formação de produtos de interesse comercial, como enzimas e ácidos orgânicos.

As enzimas são catalisadores orgânicos, geralmente de natureza protéica, que participam de várias reações bioquímicas. As enzimas, tais como poligalacturonase e pectinase são utilizadas nas 


\section{9 a 22 de outubro de 2014 \\ Florianópolis/SC}

indústrias de suco de frutas para diminuir a viscosidade do mesmo, entre outras funções (Coelho et a.l, 2001).

As pectinases formam um grupo de enzimas que degradam substâncias pécticas, hidrolisando ligações glicosídicas ao longo da cadeia carbônica. Para Uenojo e Pastore (2007) a adição de enzimas pectinolíticas nos purês de frutas e vegetais resulta na degradação da pectina e outros componentes de alto peso molecular, diminuindo a viscosidade proporcionando uma maior separação entre as fases sólidas e líquidas e aumentando o rendimento dos sucos ocasionando uma aparência cristalina no produto final e reduzindo em até 50\% o tempo de filtração assim possibilitando a oferta de um produto nobre. Já poligalacturonase é a enzima com função hidrolítica principal. Para a maioria dos usos industriais, as poligalacturonases produzidas por fungo provam ser úteis pela alta capacidade de síntese e atividade ótima em faixa de $\mathrm{pH}$ baixo, servindo para grande parte das aplicações em processos envolvendo frutas e vegetais (Santos, et al., 2008).

Entre as técnicas de fermentação, submersa e semi-sólida, a produção de enzimas geralmente prioriza a fermentação em estado sólido, por permitir produção de enzimas brutas mais concentradas e, consequentemente, com menores custos de extração e purificação (Santos, et al., 2008). O uso da fermentação semi-sólida (FSS) tem se mostrado particularmente vantajoso para o crescimento de fungos filamentosos, uma vez que simula o habitat natural destes microrganismos. Essa vantagem é estendida à produção de enzimas, proporcionando uma maior produtividade quando comparada ao processo de fermentação submersa. Além disso, as enzimas produzidas pela FSS são menos susceptíveis a problemas de inibição por substrato e, também, possuem uma maior estabilidade a variações de temperatura e $\mathrm{pH}$ (Holker et al., 2004).

Para determinar quais variáveis (umidade e proporção) foram importantes nas atividades enzimáticas de pectinase e poligalacturonase, fez-se a utilização do planejamento experimental.

Um experimento planejado é um teste, ou série de testes, no qual são feitas mudanças propositais nas variáveis de entrada de um processo, de modo a podermos observar e identificar mudanças correspondentes na resposta de saída (Montegomery, 2001).

Logo, o presente trabalho teve como objetivo utilizar a metodologia do planejamento experimental fatorial completo e análise de superfície de resposta para verificar a influência da umidade e da proporção dos resíduos (casca de coco verde e sabugo de milho) nas atividades enzimáticas de pectinase e poligalacturonase.

\section{MATERIAIS E MÉTODOS}

\subsection{Tratamento do resíduo}

Os resíduos empregados foram a casca de coco verde e o sabugo de milho. Após a seleção, os mesmos passaram por lavagem, sanitização em hipoclorito de sódio 100 ppm durante 15 min, secagem em estufa com circulação de ar a $50^{\circ} \mathrm{C}$ até se obter o peso constante para, então, serem triturados em moinho de facas tipo Wyllie e acondicionados em recipiente plástico hermético, 
mantido à temperatura ambiente.

\subsection{Microorganismo}

O microorganismo utilizado nos experimentos de fermentação foi uma linhagem de Aspergillus niger isolada do solo, gentilmente cedido pelo BIOSE da Escola de Química da Universidade Federal do Rio de Janeiro, mantidos em tubos inclinados com ágar batata dextrose (PDA), a $4^{\circ} \mathrm{C}$.

\subsection{Fermentação semi-sólida}

As fermentações ocorreram em frascos Erlenmeyer de $250 \mathrm{~mL}$, juntamente com a solução mineral, cobertos com tampão de algodão e autoclavados a $121^{\circ} \mathrm{C}$ por 15 min sendo, posteriormente, inoculados a uma taxa de $2.10^{7}$ esporos/g de substrato seco, conforme metodologia descrita por Lopes et al. (2012). As fermentações foram conduzidas a $30^{\circ} \mathrm{C}$ em estufa bacteriológica por 24 horas.

Para a extração da enzima, adicionou-se $50 \mathrm{~mL}$ de água gelada a cada frasco contendo a torta fermentada, sendo homogeneizado em incubador rotativo (shaker) à $30^{\circ} \mathrm{C}$ por um período de 30 min e filtrado em gaze para a obtenção do extrato enzimático bruto, que foi centrifugado a $3000 \mathrm{rpm}$ por 10 min para a remoção de sólidos mais finos. O sobrenadante foi filtrado em papel de filtro qualitativo e armazenado em geladeira para posterior análise de atividade enzimática (Lopes et al., 2012).

\subsection{Planejamento Experimental}

$\mathrm{Na}$ determinação das atividades da pectinase e poligalacturonase, foi estudada a influência da umidade $(\%)$ e proporção. Como variável de resposta tem-se a atividade enzimática. As variáveis independentes e seus respectivos níveis e valores reais do planejamento fatorial estão apresentados na Tabela 1.

Tabela 1 - Fatores e os níveis do planejamento fatorial $2^{2}$.

\begin{tabular}{|c|c|c|c|}
\hline \multirow{2}{*}{ FATORES } & \multicolumn{2}{|c|}{ NÍVEIS } & PONTO \\
\hline & -1 & +1 & CENTRAL \\
\hline Umidade (\%) & 60 & 90 & 75 \\
\hline Proporção & 0,5 & 1,5 & 0,1 \\
\hline
\end{tabular}

O nível de significância para os estudos da atividade da poligalacturonase e pectinase foi de $95 \%$ de confiança. O número de experimentos foi $2^{n}+3$, onde " $n$ " corresponde ao número de variáveis e o "número três" representa as três repetições no ponto central.

Foram utilizados 15 ensaios com duas réplicas cada e um planejamento fatorial completo $2^{2}$. Os ensaios foram realizados de maneira aleatória. A análise estatística dos resultados foi obtida através do programa computacional Statistic for Windows versão 7.0. 


\section{RESULTADOS E DISCUSSÃO}

A Tabela 2 mostra os resultados experimentais da atividade da pectinase e poligalacturonase, com seus valores reais e codificados, assim como as variáveis dependentes. Utilizando-se a ferramenta do planejamento experimental e análise de superfície de resposta é possível investigar a influência das variáveis em um processo e como estas variáveis se interagem, a fim de se obter valores destas variáveis que aperfeiçoem os resultados finais.

Tabela 2 - Matriz do planejamento de experimentos e atividades enzimáticas.

\begin{tabular}{cccccc}
\hline Ensaio & Réplica & Umidade & Proporção & Pectinase & Poligalacturonase \\
\hline 2 & 1 & +1 & -1 & 14,82 & 45,28 \\
1 & 1 & -1 & -1 & 7,54 & 40,71 \\
12 & 3 & +1 & -1 & 14,22 & 48,11 \\
4 & 1 & +1 & +1 & 12,71 & 39,76 \\
3 & 1 & -1 & +1 & 6,58 & 28,20 \\
7 & 2 & +1 & -1 & 12,67 & 40,43 \\
8 & 2 & -1 & +1 & 4,23 & 33,04 \\
10 & 2 & 0 & 0 & 9,81 & 42,10 \\
14 & 3 & +1 & +1 & 10,25 & 36,07 \\
5 & 1 & 0 & 0 & 9,40 & 41,28 \\
15 & 3 & 0 & 0 & 8,92 & 40,06 \\
11 & 3 & -1 & -1 & 8,15 & 35,36 \\
6 & 2 & -1 & -1 & 8,77 & 35,77 \\
9 & 2 & +1 & +1 & 12,71 & 45,91 \\
13 & 3 & -1 & +1 & 8,46 & 36,67 \\
\hline
\end{tabular}

Através do diagrama de Pareto, ilustrado nas Figuras 1 e 2, foi possível identificar estatisticamente, com 95\% de confiança, os efeitos de interação entre a umidade e proporção na síntese de cada enzima.

De acordo com a Figura 1 a umidade e a proporção foram significativas para a variável pectinase. $\mathrm{O}$ mesmo não ocorre com a interação entre as variáveis independentes (umidade e proporção). 
(1) Umidade (\%)

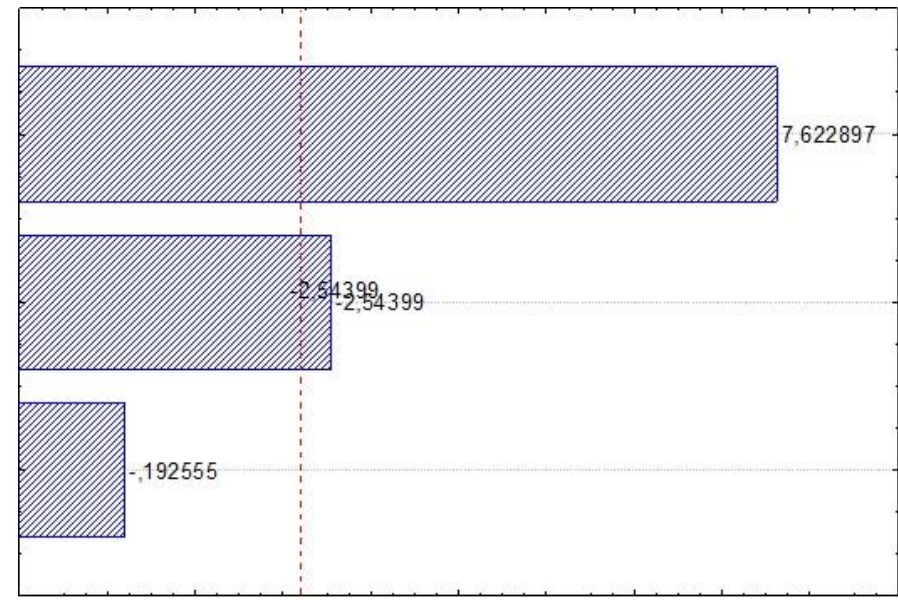

Figura 1 - Diagrama de Pareto dos efeitos das variáveis umidade e proporção para a atividade enzimáticas da pectinase e para o consumo de açúcares no tempo 24 h de fermentação.

(1) Umidade $(\%)$

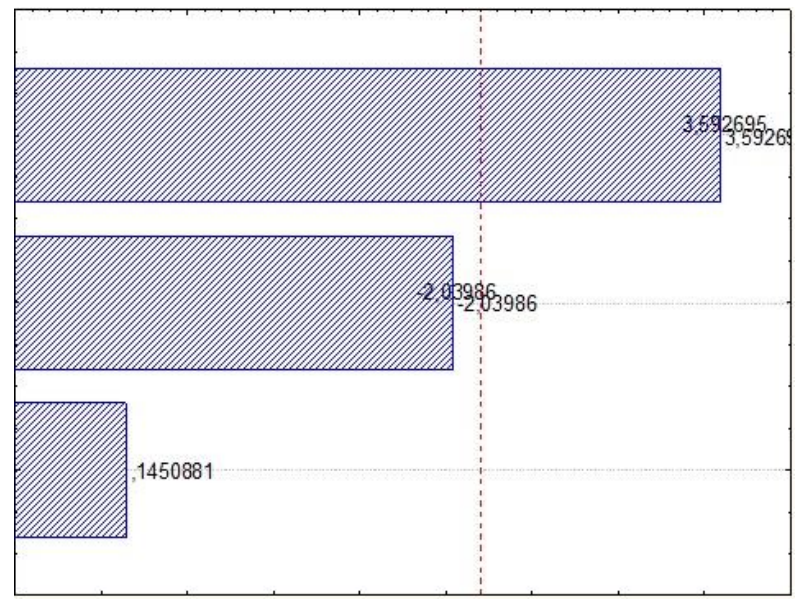

$\mathrm{p}=0,5$

Figura 2 - Diagrama de Pareto dos efeitos das variáveis umidade e proporção para a atividade enzimática da poligalacturonase no tempo $24 \mathrm{~h}$ de fermentação.

Analisando os resultados para a poligalacturonase (Figura 2), verifica-se que dos dois efeitos principais, somente a umidade foi significativa. Não há evidências de interação de nenhum deles, logo o efeito da umidade pode ser interpretado isoladamente.

As Figuras 3 e 4 apresentam as superfícies resposta das atividades de pectinase e 


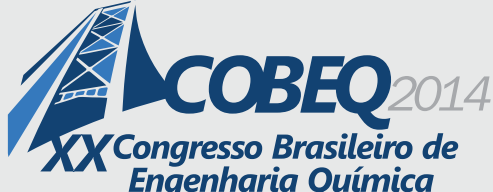

poligalacturonase, respectivamente.

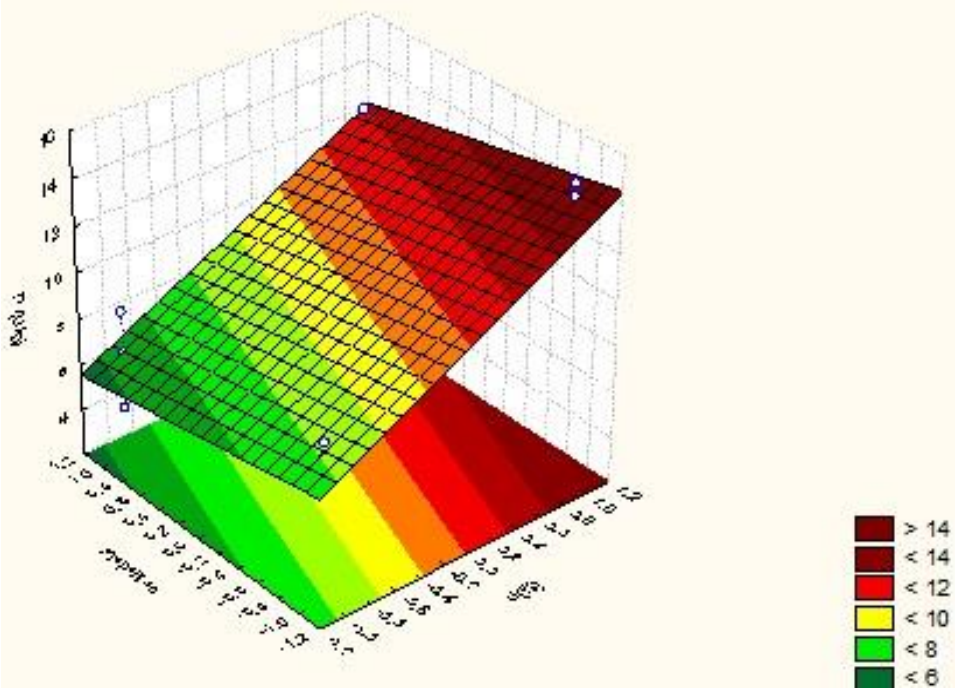

Figura 3 - Superfície de resposta obtida para a atividade enzimática da pectinase em função da umidade e proporção em 24 h de cultivo

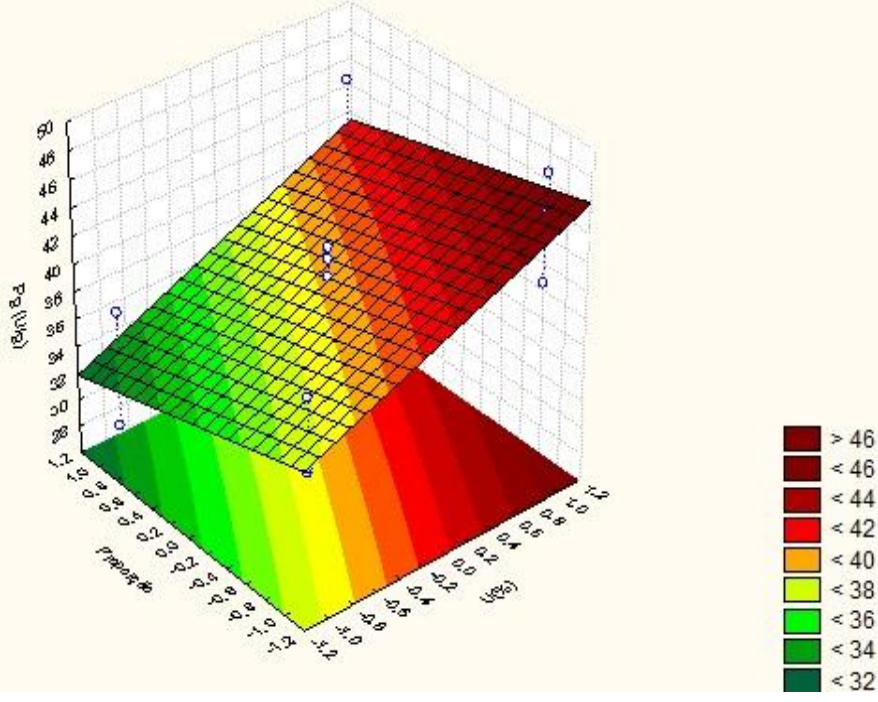

Figura 4 - Superfície de resposta obtida para a atividade da enzima poligalacturonase em função da umidade e proporção em $24 \mathrm{~h}$ de cultivo

Analisando as Figuras 3 e 4 observa-se que a proporção não influencia a atividade de pectinase e poligalacturonase e que quanto maior a umidade, maior é a síntese enzimática, sendo, a umidade no valor de $90 \%$ a melhor condição de umidade para o desenvolvimento destas 
enzimas. A maior atividade enzimática obtida das enzimas em estudo pode ser observada na Figura 5.

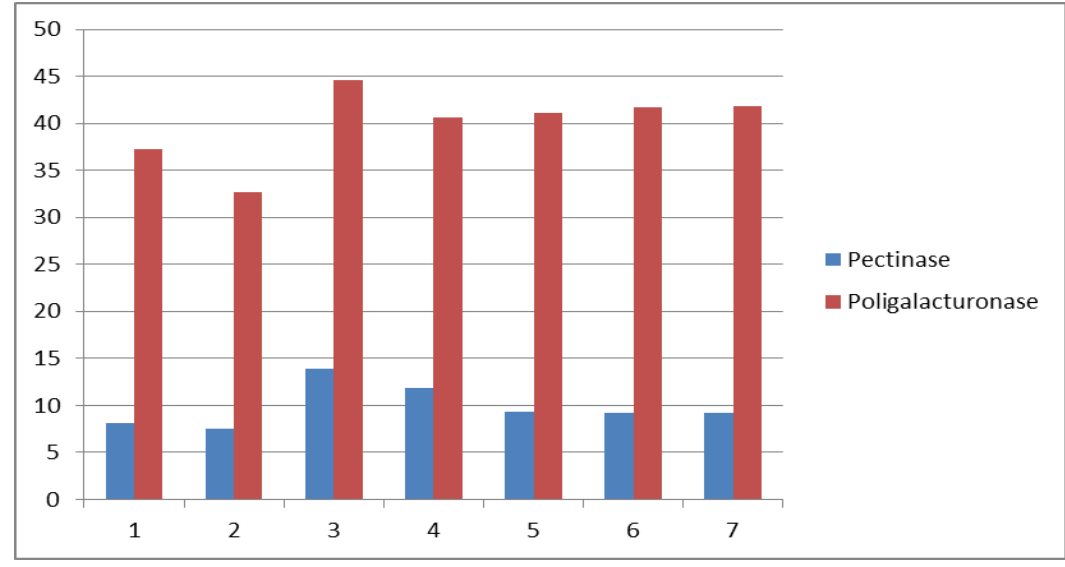

Figura 5. Gráfico de comparação da atividade enzimática da pectinase e poligalacturonase

De acordo com a Figura 5, a maior atividade enzimática foi da poligalacturonase comparada com a pectinase, ambas em $24 \mathrm{~h}$ de fermentação.

\section{CONCLUSÕES}

Os resultados mostraram que a fermentação semi-sólida constitui-se numa alternativa de aproveitamento de resíduos agroindustriais. A utilização da casca de coco verde e sabugo de milho como substrato mostrou a capacidade da produção de enzimas, permitindo alcançar as maiores atividades de poligalacturonase e pectinase, em 24 horas de fermentação, com os valores 45,08 e $13,76 \mathrm{U} / \mathrm{g}$, respectivamente.

\section{REFERÊNCIAS}

ARAÚJO, M. L.; ALMEIDA, R. M. R. G.; ABUD, A. K. Produção de enzimas por fermentação semi-sólida a partir de resíduos da casca de coco verde. XIX Congresso Brasileiro de Engenharia Química, Búzios/RJ, 2012.

CALADO, V., MOTGOMERY, D. Planejamento de Experimentos usando o STATISTICA. Rio de Janeiro: E-papers, 2003.

COELHO, M. A. Z.; LEITE, S. G. F.; ROSA, M. F.; FURTADO, A. A. L. Aproveitamento de resíduos agroindustriais: produção de enzimas a partir da casca de coco verde. B.CEPPA, Curitiba, v. 19, p. 33-42, 2001. 
MONTGOMERY, D.C. Desing and analysis of experiments, 5th edition. New York, Willey, 2001.

NOGUEIRA, A. et al. Avaliação da trituração e tratamentos enzimáticos na obtenção de suco de maçã por centrifugação. Ciências Exatas e da Terra, Ciências Agrárias, v. 11, p. 7-12, 2005.

SANTOS, S. F. M.; SOUZA, R. L. A.; ALCÂNTARA, S. R.; PINTO, G. A. S.; SILVA, F. L. H.; MACEDO, G. R. Aplicação da metodologia de superfície de resposta no estudo da produção de pectinase por fermentação em estado sólido do pedúnculo de caju. Revista Brasileira de Produtos Agroindustriais, Campina Grande, v.10, p.101-109, 2008.

UENOJO, M.; PASTORE, M. G. Pectinases: aplicações industriais e perspectivas. Química Nova, v. 30, p. 388-394, 2007. 